\title{
UTERINE RUPTURE;
}

\author{
ITS MATERNAL CONSEQUENSES
}

\section{Dr. Chandra Madhudar, Dr. Ambreen Ghori, Dr. Farkhunda Khurshid, Dr. Syed Zulfiquar Ali Shah, Dr. Tarachand Devrajani.}

ABSTRACT......objective: To evaluate frequency, maternal morbidity and mortality in patients with uterine rupture at Gynae Unit -II of civil Hospital Hyderabad. Study design: Prospective descriptive study. Study setting: Department of Obstetrics and Gynecology, unit-II Liaquat University Hospital Hyderabad Sindh Pakistan; from 1st October 2010 to 31 st March 2011. Subjects and methods: All the patients diagnosed as case of uterine rupture was taken as study subject. Data was collected in a pre-designed porforma. Variable analyzed were frequency, demographic characters, maternal morbidity and mortality. Results: During the study, 34 patients out of 1400 deliveries presented with uterine rupture resulting in a frequency of $2.42 \%$ or $1: 41$ deliveries. $64.7 \%(22)$ patients were between 26 to 35 years age and $67.64 \%(23)$ were multipara.26.47\%(9) presented with extension of tears, $17.6 \%(6)$ with shock,20.5\%(7) with septicemia and $20.5 \%(7)$ with wound infection. Conclusions: Uterine rupture is yet a common obstetrical emergency in our area. The significant morbidity and mortality deserves our special attention by a collaborative approach. Regular ante natal checkups, careful selection of patients for vaginal delivery, vigilantly monitoring during labor with smooth switch over to operative delivery can reduce this drastic obstetrical complication.

Key words: Uterine rupture, maternal morbidity, maternal mortality.

Article Citation

Madhudas C, Ghori A, Khurshid F, Shah SZA, Devrajani T. Uterine rupture; ITS maternal consequenses. Professional Med J 2013;20(5): 726-730.

\section{INTRODUCTION}

Uterine rupture is one of the preventable catastrophic complications in obstetric care and a major cause of maternal morbidity and mortality ${ }^{1}$. It may occur in previously intact uterus or in one with a previous cesarean or Myomectomy scars. It usually follows the course of labor; however one third of uterine scar following earlier cesarean section (classical) may rupture during third trimester before term and before the onset of labor ${ }^{2}$. Incidence of uterine rupture is $0.05 \%-0.086 \%$ of all pregnancies ${ }^{3}$, but varies world wide ranging between 2.4 to 8.9 per1000 deliveries, which is a reflection of the standard of obstetric care and access to $\mathrm{it}^{4}$. It is rarely encountered in developed countries with an overall incidence of 1:1536 pregnancies $(0.07 \%)^{5}$, but in the developing countries, it is still at the dock, especially in Pakistan, due to illiteracy, male dominant society and untrained birth attendant. Majority of population living in rural areas do not have an easy accessibility to a maternity and essential obstetric care. Therefore they may develop life threatening complications of pregnancy and the fatality rate associated with ruptured uterus is very high $^{6}$.

Uterine rupture has different causes, unlike in the developed world where excessive and prolonged use of oxytocin in the presence of scarred uterus is the major cause. In less developed countries, feto-pelvic cause disproportion, causing obstructed labor, is the major cause of uterine rupture ${ }^{7-9}$.

In developing countries where maternal mortality rate is100-200 times higher than Europe and North America $10 \%$ of maternal deaths are due to uterine rupture $^{10}$. Delay in management places both mother and fetus at significant risk. Major maternal complications are hemorrhage, shock, post-operative infections, bladder damage, uretric damage, thrombophlebitis, amniotic / pulmonary embolism, disseminated intravascular coagulation and death ${ }^{2}$.

Our unit being a part of tertiary care center receives a high number of patients having uterine rupture from peripheral remote area, maternity clinics and nursing home, with significant adverse outcome and this has 
drawn our attention to evaluate the spectrum of problem. This study will also help to identify the changing trends in our area and to plan the appropriate guidelines for making the pregnancy and labor a safe event.

\section{PATIENTS AND METHODS}

This prospective study was conducted at gynecology unit II of LUHMS from $1^{\text {st }}$ October 2010 to $31^{\text {st }}$ March 2011.Departmental Approval for study was obtained. All patients admitted in labor room either clinically diagnosed as rupture uterus or patient with silent rupture at term were taken as study subject. Exclusion criteria were no consenting women and patients with gestational age less than 37 weeks. Data were collected on specially designed proforma. Variable analyzed were frequency, demographic characters, maternal morbidity and mortality. Data was analyzed in SPSS version 16.

\section{RESULTS}

Out of 1400 deliveries there were 34 cases of uterine rupture during study period giving frequency of 1:41 or 2.42\%. 64.7\%(22) patients were un booked while $35.29 \%$ ( 12) were booked. (23) $67.64 \%$ were multipara, $9(26.47 \%)$ were grand multipara and 2 (5.88\%) were primipara. $64.7 \%$ patients 22 were between age group 26-35 years and 04 (11.76\%) were between 36-42 years of age. Table.ll shows various maternal morbidities due to uterine rupture. $29(85.2 \%)$ patients under went uterine repair while $2(5.88 \%)$ patients ended up with hysterectomy and $1(2.94 \%)$ patient had bladder repair. Two patients died soon after admission without surgical exploration. $9(26.47 \%)$ patients had extension of tears, $7(20.5 \%)$ patients had wound infection and sepsis while $6(17.6 \%)$ patients were received in shock. 5(14.7\%) patients had UTI and post partum hemorrhage. 2(5.88\%) patients had post partum depression and blood transfusion reaction. Other complications like DVT, fistula formation, aspiration pneumonia and acute renal failure each observed in 1 patient (2.94\%).
Majority of patients had a combination of morbidities.

\begin{tabular}{|c|c|c|}
\hline Variable & Number & Percentage \\
\hline $\begin{array}{c}\text { Age } \\
15-25 \\
26-35 \\
36-42\end{array}$ & $\begin{array}{l}08 \\
22 \\
04\end{array}$ & $\begin{array}{c}23 \\
64.7 \\
11.76\end{array}$ \\
\hline $\begin{array}{c}\text { Parity } \\
\text { PG } \\
\text { Multigravida } \\
\text { Grandmultigravida }\end{array}$ & $\begin{array}{l}02 \\
23 \\
09\end{array}$ & $\begin{array}{l}5.88 \\
67.64 \\
26.47\end{array}$ \\
\hline $\begin{array}{l}\text { Booking status } \\
\text { Un-booked } \\
\text { Booked }\end{array}$ & $\begin{array}{l}22 \\
12\end{array}$ & $\begin{array}{c}64.7 \\
35.29\end{array}$ \\
\hline $\begin{array}{c}\text { Gestational age } \\
36-38 \\
39-40\end{array}$ & $\begin{array}{l}21 \\
13\end{array}$ & $\begin{array}{l}61.76 \\
38.23\end{array}$ \\
\hline
\end{tabular}

\begin{tabular}{|c|c|c|}
\hline Material Morbidities & Number & Percentage \\
\hline Extension of tears & 09 & $26.47 \%$ \\
\hline Wound infection & 07 & $20.5 \%$ \\
\hline Sepsis & 07 & $20.5 \%$ \\
\hline Shock & 06 & $17.6 \%$ \\
\hline UTI & 05 & $14.7 \%$ \\
\hline Post partum hemorrhage & 05 & $14.7 \%$ \\
\hline Post partum depression & 02 & $5.88 \%$ \\
\hline Blood transfusion reaction & 02 & $5.88 \%$ \\
\hline Hystrectomy & 02 & $5.88 \%$ \\
\hline DVT & 01 & $2.94 \%$ \\
\hline Fistula formation & 01 & $2.94 \%$ \\
\hline Aspiration pneumonia & 01 & $2.94 \%$ \\
\hline Acute renal failure & 01 & $2.94 \%$ \\
\hline Bladder repair & 01 & $2.94 \%$ \\
\hline No. of Maternal deaths & 02 & $5.88 \%$ \\
\hline Table-II. Maternal morbidities (n=34) & \\
\hline Majority of patients had a combination of morbidities \\
\hline
\end{tabular}

\section{DISCUSSION}

The frequency of ruptured uterus in our study is 1:41 deliveries (2.42\%), while it varies between 2.4 and 8.9 per 1000 deliveries in different studies ${ }^{4}$. 64.7\% patients in our study were un-booked indicating a 
major contributing factor for maternal morbidity and mortality with uterine rupture. In a study by Anjum in Karachi revealed that "women receiving antenatal care were more knowledgeable about the importance of nutrition and health awareness ${ }^{11}$. Furthermore, it is evidenced in a number of studies that when a comprehensive antenatal care programmed is implemented, it has reduced the incidence of uterine rupture by almost five times ${ }^{12}$. Simple interventions like antenatal, provision of health care services at rural health centers and strengthening of obstetric care services at every level of health care facility can significantly reduce these deaths.

Multiparty is still a predisposing factor in Pakistan, a country of a high fertility rate (6.5), it could be one of the major factor for uterine rupture. In our study $67.64 \%$ patients were multipara, which is similar to the findings of Faleyimu BL, et al from Nigeria ${ }^{13}$. The results are also in good agreement with other Pakistani's studies such as Munim ${ }^{14}$ and Malik ${ }^{15}$ studies. Thus this major factor can only be minimized by offering postpartum contraception and highlight the importance of fertility regulation at community level.

Maximum cases were seen in age group of 25-35 years (64\%). The same result was reported by Malik at Jinnah Medical College Hospital, Karachi and Khan, et $\mathrm{al}^{6}$ at Ayub hospital Abbottabad.

In our study, previous scarring of the uterus has emerged as the greatest single predisposing factor to uterine rupture of pregnancy; $79 \%$ of all ruptures occurred in the presence of a scar, of which $42 \%$ were silent in nature and were discovered at the time of elective repeat caesarean section. Our result does correlate with those of James GD study ${ }^{16}$. Such data uphold the dictum, "once a caesarean section always a caesarean. With this changing trend in causative factors, the most important single element in preventing rupture of the uterus like in adherence to strict indications for the first caesarean section.
Prolonged obstructed labor, is no more a contributor for rupture of uterus in the developed countries ${ }^{17,18}$ However $38.23 \%$ cases in current study had contributed to uterine rupture. This was in correlation with the reports from $\mathrm{WHO}^{19}$, Ezechi ${ }^{1}$ from Nigeria (91.8\%) and Chuni $\mathrm{N}^{20}$ from Nepal (46.5\%). It is ridicules that majority of the patients had their trial of labor at nearby clinics or local maternity homes under supervision of nurses, lady health visitors and doctors, yet there was a delay in decision making for operative delivery. In Pakistan, currently there is no governing body to check the standards and quality of obstetric care provider by such centers and the establishment of such system is the need of the day to avoid these obstetrical mishaps.

One case of bladder rupture in our study was exclusively associated with case of rupture with lower uterine segment. These finding were similar to other studies $^{8,21}$.This may be due to caesarean section performed by operator with poor surgical skills or in setting with poor aseptic operational techniques, both leading to poor scar integrity.

Blood availability and transfusion in catastrophic events like uterine rupture, is a life saving factor ${ }^{22}$. This study had showed that a common scenario is that of an already anemic patient with heavy bleeding and poor availability of blood transfusion, which is a problem in nearly all the hospitals of our setup. $55.8 \%$ patients had transfusion of 2-4 unit of blood before and during the operation, which was similar with the results of study conducted in Yemen ${ }^{22}$. Blood availability is a real problem, there is need is to improve blood supply through functional blood banking services especially during peri-operative period. 2 $(5.88 \%)$ of our patients had blood transfusion reaction. Hysterectomy was required in $5.88 \%$ patients with spontaneous rupture because of extensive laceration and intractable hemorrhage which was lower than Garnet $^{16}$ study (85\%). In our study, decision to conserve or sacrifice the uterus was influenced by the 
condition of uterus, age, fertility wishes and socio cultural acceptability. $82 \%$ of cases in our study were anemic that is quite closer with Yemen study ${ }^{22}$ while it is higher than the study of James $\mathrm{GD}^{16}$. Extension of tears, wound infection, and sepsis were the most common immediate causes of maternal morbidities associated with uterine rupture. Timely diagnosis of uterine rupture and appropriate management can minimize these complications.

We found a high incidence of maternal death related to uterine rupture $(5.88 \%)$ more than reported by Qadeer $S$ that is 2.123 However, our results are comparable with those of Malik, et al and Rehman J, et al $(5 \%)^{15,24}$. The main cause of death was Hypovolemic shock and anemic failure. The intensity of initial resuscitation and speed of surgical rescue play a major role in determining maternal outcome.

No one can deny the negative impact of uterine rupture on maternal and child birth. In Pakistan, there is a tremendous need for expansion of maternal and child health services in urban and more importantly in rural areas. There should be a well organized programmed for the training of traditional birth attendants. Maternity care services need to be improved for early diagnosis of uterine rupture, enhancement of nutrition, reduction of anemia and provide free treatment at teaching hospitals for a favorable feto-maternal outcome.

\section{CONCLUSION}

Ruptured uterus continues to be a recurring obstetrical disaster in the developing world with its associated mortality and morbidity. In Pakistan uterine rupture is still a major health problem with the rate being high in rural areas. Socio-economic, cultural factors and shortcomings in health services play major roles in determining the frequency of uterine rupture. However, many efforts have proven insufficient and ineffective in reducing feto-maternal mortality in general because the issue is viewed as a medical or clinical dilemma rather than a broader public health problem.

\section{Copyright@ 15 Mar, 2013.}

\section{REFERENCES}

1. Ezechi OC, Mabayoje, Obiesie LO. Rupture uterus in South east Nigeria a reappraisal. Singapore Med J.2004:45:113-6.

2. Clay don C.S. pernoll L. Mortin. Third Trimester Vaginal bleeding. Current Obstetrics and Gynecology Diagnosis and treatment 9th edition. 2007;365-367.

3. Eden RD, Parker RT, Gall SA: Rupture of the pregnant Uterus: A 53 - year review. Obstet Gynecol. 1986; 6868:671-67.

4. Agboola A. Rupture of the uterus. Nig. Med J.1973:2:19-21.

5. Uterine Rupture in Pregnancy: [Print] e - Medicine Obstetrics and Gynecology.http://emedicine.med scape. com/article/ 275854-print.

6. Khan S, Parveen Z, Begum S, Alam I. Uterine rupture: a review of 34 cases at Ayub Teaching Hospital Abbottabad. J Ayub Med Coll Abbottabad. 2003;15(4):50-2.

7. Saglamtas M, Vic Dan K, Yalcin H, Yilmaz Z. Rupture of the uterus. In J Gynecol Obstet.1995; 49(1):9-15.

8. Gardeil F, Daly S, Turner MJ. Uterine rupture in Pregnancy reviewed. Eur J Obstet Gynecol Reprod Biol.1994;56 (2):107-10.

9. Diallo FB, Idi N, Vangeenderhuysen, Baraka D, Hadiza I, Garba M, et al. Uterine Rupture at the Niamey Central Maternity Reference Nigeria. Dakar Med 1998; 43(1):74-8.

10. Landon MB, Hauth JC, Leveno KJ, Spong CY, Leindecker S, Varner MW, et al. Maternal and Perinatal outcomes associated with a trial of labor after Prior cesarean delivery. N Engl J Med. 2004;351(25):25819.

11. Anjum Q. Girls child today. Mother of a nation tomorrow. Editorial. J Pak Med Assoc. 2005;55:51.

12. Donald I. Maternal Injuries. In Practical Obstetrics Problems 5th edition 1983. Hong Kong. PG Publishing 
(Pvt.) Ltd, pp 795 - 803.

13. Faleyimu BL, Makinde 00. Rupture of the gravid uterus in Ile-Ife, Nigeria. Tropical Doctor.1990;20:188-189.

14. Munim TF, Hussain SMA, Usman E, Raza BSM, Rehman A. Ruptured uterus: A three years study. J Surg Pak.2002;7:6-8.

15. Malik HS. Frequency, predisposing factors and feto maternal out Come in uterine rupture. J Coll Physicians Surg Pak.2006; 16(7):472-5.

16. James GD. Uterine Rupture during Pregnancy: An Analysis of 133 Patients. 807 Spruce St. Philadelphia, 2006.p.19107.

17. Ezegyui HU Nwogu, Ikojo EE. Uterine repture in Enugu, Nigeria. J Obstet Gynecol.2005;25:260-2.

18. Stephine Yap OW, Kin ES, Laros HR. Maternal and neonatal Outcome After uterine rupture in Labour. Am J Obstet Gynecol. 2001;184(7):1576-81.
19. Justus Hofmeyr G, Say L, Metin-Gulmezoglu A. WHO systemic review of maternal mortality and morbidity. 2005; 112:1221-8.

20. Chuni N. Analysis of uterine rupture in a tertiary centre in Eastern Nepal: lessons for obstetric care. $J$ Obstet Gynecol Res.2006; 32:574-9.

21. Iloki LH, Okongo D, Ekoundzola JR. Uterine rupture in an African environment. J Gynecol Obstet Biol Reprod 1994;23(8):922-5.

22. Dhaifalah Ishraq. Santavy Jiri. Uterine rupture Pregnancy and delivery among women attending the Al-Tthawra Hospital in Sana'a city. Yemen republic Department of human genetic and fetal medicine. 2006(3).1:122-25.

23. Qadeer S. Management of ruptured uterus. J Coll Physician Surg Pak.1999;9:190-2.

24. Rahman J, Al-Sibai MH, Rahman MS. Rupture of the uterus in Labour. A review of $\mathbf{9 6}$ cases. Act an Obstet Gynecol Scand.1985;64(4):311-5.

\section{AUTHOR(S):}

1. DR. CHANDRA MADHUDAR

Department of Obstetrics \& Gynaecology

Liaquat University of Medical \& Health Sciences, Jamshoro.

2. DR. AMBREEN GHORI

Department of Obstetrics \& Gynaecology

Liaquat University of Medical \& Health Sciences, Jamshoro.

3. DR. FARKHUNDA KHURSHID

Department of Obstetrics \& Gynaecology

Liaquat University of Medical \& Health Sciences, Jamshoro.

4. Dr. Syed Zulfiquar Ali Shah

Department of Medicine

Liaquat University of Medical \& Health Sciences, Jamshoro.
5. Dr. Tarachand Devrajani

Department of Medicine

Liaquat University of Medical \& Health Sciences, Jamshoro.

Correspondence Address:

Dr. Syed Zulfiquar Ali Shah

House No. 279, Doctor's Colony Hirabad Hyderabad,

Sindh, Pakistan.

zulfikar229@hotmail.com

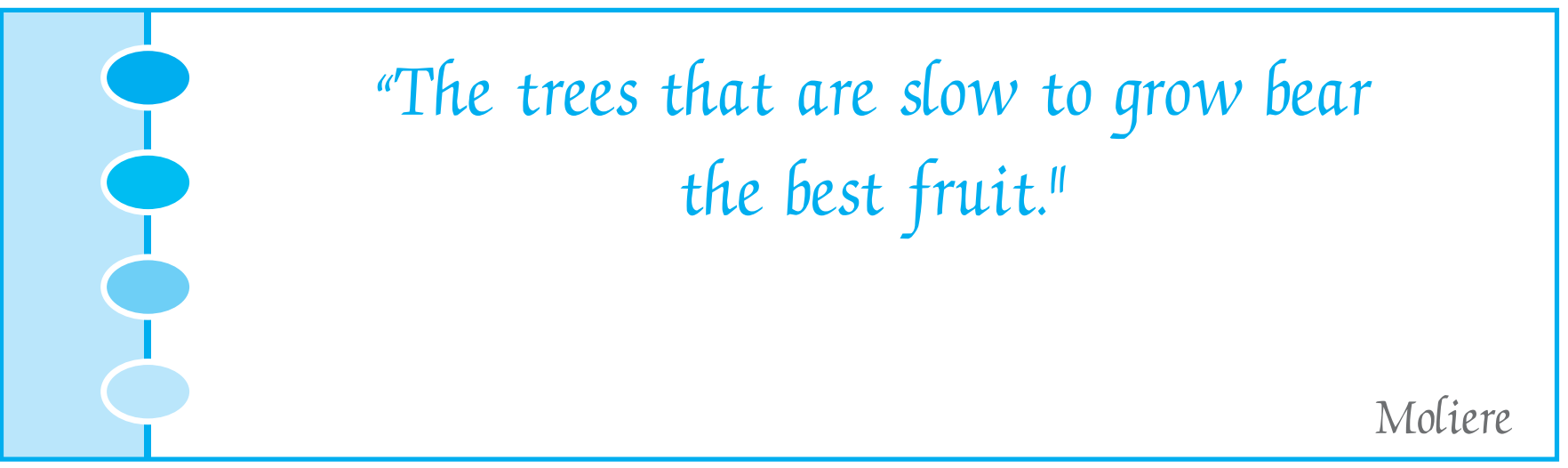

